Egyptian

Orthodontic Journal

\title{
MICROLEAKAGE UNDER POLYCARBONATE AND METALLIC BRACKETS BONDED WITH RESIN - MODIFIED GLASS IONOMER VERSUS LIGHT CURED COMPOSITE RESIN
}

\author{
Aly $\mathrm{D}^{*}$, Tamish $\mathrm{N}^{* *}$, Ismail $\mathrm{H}^{* *}$
}

ABSTRACT:

Objective: An in vitro study to evaluate the microleakage at the occlusal and gingival margins of 6oth polycarbonate and metallic brackets bonded with light-cured resin modified glass ionomer cement versus light cured composite.

Materials and Methods: 40 extracted sound premolars were divided into 2 groups. Group I was bonded with polycarbonate brackets (silkon $\mathcal{M} \mathcal{T M}$ ). 10 samples using light cure Fuji ortho (IA) and 10 samples using Trans bond XT (IB). Group II was bonded with metal brackets using both techniques (IIA\&ZIIB). All samples were then subjected to thermo cycling. The root apices were sealed with sticky wax and the teeth were painted with 3 layers of nail polish leaving a $1 \mathrm{~mm}$ window surrounding the bracket. Teeth were then immersed in $0.5 \%$ basic fuchsine dye solution for 24 hours at room temperature then washed under running water and sectioned longitudinally between the bracket wings into two halves using a low speed thin diamond disc under a stream of water. The extent of dye penetration was detected using a light stereomicroscope (X18 magnification) at 6oth the occlusal and gingival areas of the brackets between both the enamel adhesive and the bracket adhesive interphases using soft imaging analysis. Descriptive statistics were computed as means and standard deviations of micro leakage values in different groups. Pooled micro leakage allowed the use of ANOVA, Tukey

\footnotetext{
* Post graduate student, Orthodontic department faculty of dentistry, Alexandria University.

** Professor of Orthodontics, faculty of dentistry, Alexandria University.
} 
HSD test and the general linear model test at $p<0.05$. Significance level was set at 5\%. Statistical analysis was done using SPSS version 17.Bar charts with Error bars were used for graphical presentation. Results: The gingival side of all groups exhibited higher microleakage compared with the occlusal side for both adhesive interfaces. All bracket and adhesive combinations displayed statistically significant differences in microleakage between the enamel-adhesive and adhesive-bracket interfaces at the occlusal and gingival sides of the brackets. When the adhesive systems were compared, the Resin Modified Glass Ionomer cement (RMGIA) showed more microleakage than the light cured composite resin between the different interfaces. The polycarbonate brackets with the addition of ceramic fillers showed more microleakage than metallic brackets. Conclusion: The overall comparison of the bonding system used revealed that no combination was found to be superior in their microleakage infibition property, and polycarbonate brackets even by addition of ceramic fillers seemed that it was still inferior to the metallic brackets in the microleakage infibition property.

\section{INTRODUCTION}

From the orthodontic point of view, microleakage presents the formation of white spot lesions under the bracket surface area. ${ }^{(1)}$ The clinical symptoms associated with microleakage are breakdown and discoloration of margins, secondary caries, increase in postoperative sensitivity and pulp pathology. ${ }^{(2)}$ Microleakage between compositeenamel interface is the average of two of three teeth bonded with the bonding materials which are affected by some form of enamel opacity or diffuse opacity after orthodontic treatment. ${ }^{(3,4)}$ Demineralization of enamel occurs due to organic acids produced by bacteria in dental plaque surrounding the orthodontic appliances. ${ }^{(5,6)}$

James et $\mathrm{al}^{(1)}$ were the first to point out increased risk of decalcification caused by micro leakage around orthodontic brackets. Many efforts has been done to overcome the demineralization process around the orthodontic brackets including daily use of a fluoride rinse combined with oral hygiene instruction which can lead to a significant reduction in decalcification. ${ }^{(5)}$ 
Egyptian

Orthodontic Journal

Although plastic brackets were introduced with considerable enthusiasm, they are not durable enough to hold up in the mouth for long term because of many reasons ${ }^{(7-10)}$, however their lower prices and the hazardous effects of the ceramic brackets on the enamel made them popular especially ceramic reinforced plastic brackets and those with metal slots.

Several factors affect the integrity of the adhesives interfaces and can contribute to microleakage. These factors include: polymerizationshrinkage ${ }^{(11)}$, thickness and type of the adhesive ${ }^{(12)}$, coefficient of thermal expansion ${ }^{(13)}$, light polymerization units ${ }^{(14)}$, thermo cycling ${ }^{(15)}$, acid-Etch Technique ${ }^{(16)}$, adhesive bond strength ${ }^{(17)}$.

\section{MATERIALS AND METHODS}

The selected sample of this study consisted of forty extracted human first upper and lower premolars collected from patients seeking orthodontic treatment whose treatment plan indicated extraction of maxillary and/or mandibular first premolars at Orthodontic Department, Faculty of Dentistry, Alexandria University. The inclusion criteria were sound freshly extracted teeth i.e. free from any decay, and restoration with visually intact enamel surface.

Two different types of orthodontic brackets for bonding were used: Twenty standard mesh base edgewise stainless steel brackets (Mini Standard Edgewise. American orthodontics. Sheboygan, WI USA).

Twenty straight clear plastic with ceramic like filler polycarbonate brackets (Silkon M TM. American orthodontics. Sheboygan, WIUSA.).

Two different types of bonding materials were selected Transbond XT light cure composite (Transbond TM XT. 3M UNITEK. Monorvia, California, USA) and Fuji Ortho LC TM light cure resin reinforced glass ionomer cement (FUJI ORTHO LC, GC corporation, Tokyo, Japan). Orthodontic conditioner for RMGI cements (Poly-acrylic acid dentin conditioner. GC Corporation, Tokyo, Japan) .10\%polyacrylic acid supplied in the form of a bottle of $23.8 \mathrm{ml}$. Etching gel: 37\% Ortho-phosphoric acid (Phosphoric Acid Etching Gel, $37 \%$ conc. 3M EPSE AG, Germany.) 
Egyptian

Orthodontic Journal

\section{The samples were divided into the following four groups:}

Group I: Twenty teeth used with polycarbonate brackets. This group was further subdivided into 2 groups:

Group IA: Ten teeth etched using etching gel then conditioned with polyacrylic acid followed by bonding of polycarbonate brackets with resin-modified glass ionomer.

Group IB: Ten teeth etched using etching gel and polycarbonate brackets bonded using composite resin.

Group II: Twenty teeth to be used with metal brackets. This group will be subdivided into 2 groups:

Group IIA: Ten teeth etched using etching gel then conditioned with polycyclic acid and metal brackets bonded using resinmodified glass ionomer.

Group IIB: Ten teeth etched using etching gel and the metal brackets will be bonded with composite resin.

$\checkmark$ The extracted premolars were washed from debris and blood stain then kept in distilled water solution until the time of preparation. Enamel surface to be bonded was given a thorough prophylaxis using pumice paste and water containing no oil or fluoride .The paste was applied using rubber cup rotated at a low speed on a conventional handpiece for 10 seconds. Then the enamel surface was rinsed thoroughly with water syringes and dried with an oil and moisture free source using hair dryer.

1- Acid etching and dentine conditioner:

- For all groups: Acid etching was carried out by one or two drops of the acid etching gel (37\%) orthophosphoric acid which was dispensed on a dispensing pad. Tweezer was used to saturate a disposable mini-sponge applicator with the etchant then dabbed gently and continuously on the enamel. The acid must not be rubbed because this would reduce the depth of the enamel pockets which form the major source of retention. Pressure was avoided since this could destroy the relative characteristics of the etched surface. After 30 seconds etching the teeth surfaces were then rinsed thoroughly with an air water syringe for 20 seconds in order to wash the enamel surface from the residual acid etchant. The etched surface was dried using the hair dryer until the buccal surface of the teeth appeared chalky white. 
- For groups IA \& IIA: Dentine conditioner was carried out by one or two drops of the conditioner (polyacrylic acid) which dispersed on the dispensing pad. A disposable mini-sponge applicator was used to apply the conditioner to the bonding surface for 20 seconds. The bonding surface was rinsed thoroughly with a water syringe then dried by blotting using cotton pellet until it appeared moist (glistening) as indicated by manufacture's instruction.

2- Application of direct bonding material and brackets placement:

- For groups IA \& IIA, Resin-modified glass ionomer adhesive: The powder and liquid were in a ratio of 3: 1 gm adjusted by large spoon of powder to 2 drops of liquid. The bases of the brackets were coated completely with the mixed adhesive. The metallic and polycarbonate brackets were placed using clamping tweezers on the prepared enamel. After bracket positioning, the bracket was pressed firmly on the tooth surface in order that the excessive adhesive came out then the excess was removed by dental probe.

The adhesive was then cured through its exposure to the light curing source using the conventional halogen light curing unit by placing the light guide about $2 \mathrm{~mm}$ away from the bracket and shine the light through the bracket. Each bracket was exposed to the light for 10 seconds from the occlusal, mesial, distal and gingival aspects according to the manufacturer's instructions.

- For groups IB and IIB, Light-cure composite resin adhesive: After etching transbond XT primer was placed on a cotton pellet. A thin uniform coating of primer was applied onto the surface to be bonded using the enclosed disposable brushes. The primer coating was then subjected to the conventional halogen light-curing unit for 20 seconds. Using syringe a small amount of transbond XT adhesive paste was applied on the bracket base. The bracket was lightly placed on the tooth surface. Bracket adjustment was done in the position with pressure using holding tweezer. The excess adhesive was gently removed using dental probe form around the bracket base without disturbing the bracket.

The resin was then cured through its exposure to the light-curing source using the conventional halogen light-curing unit by placing the 
light guide approximately $2 \mathrm{~mm}$ away from the bracket and shining the light through the metallic and polycarbonate brackets.

Each bracket was exposed to four light exposures from four different sides, occlusal, mesial, distal and gingival aspects to ensure getting complete polymerization. Each exposure time was of 10 seconds.

\section{3-Thermocycling:}

The teeth were thermocycled in a water bath for 500 cycles using the thermocycling machine, alternating between $5^{\circ} \mathrm{C}$ and $55^{\circ} \mathrm{C}$ with a dwell time 30 seconds.

After thermocycling, the samples were stored in a water bath at room temperature till the time of microleakage testing.

4- Microleakage testing:

- The root apices were sealed with sticky wax.

- The teeth were rinsed in tap water and air dried.

- Tooth surfaces were coated with three layers of nail polish except for an area approximately $1 \mathrm{~mm}$ away from the bracket.

- The teeth were replaced in water as soon as the nail polish dried to minimize the dehydration of the restoration.

- Then the teeth were immersed in $0.5 \%$ basic fuchsine solution for 24 hours at room temperature.

- The teeth were removed from the dye solution and washed under running water and the superficial dye was removed with a brush and dried.

- Then the teeth were sectioned longitudinally between bracket wings into two halves using a low-speed thin diamond disc under stream of water to prevent damage of the tooth from heat generation.

- The extent of dye penetration was detected by light stereomicroscope (X18 magnification) using soft imaging analysis at both the occlusal and gingival areas of the brackets at the enamel-adhesive and the adhesive-bracket interfaces.(OLYMPUS stereomicroscope SZII) 
Egyptian

Orthodontic Journal

\section{STATISTICAL ANALYSIS}

Descriptive statistics were computed as means and standard deviations of microleakage values in different groups. Normality of values was checked using skewness, kurtosis and Kolmogrov Smirnov test. Pooled microleakage for all groups proved to be normally distributed and allowed the use of ANOVA, Tukey HSD test and the General Linear Model test. Significance level was set at 5\%. Statistical analysis was done using SPSS version 17.Bar charts with Error bars were used for graphical presentation.

\section{RESULTS}

Table I shows the mean and standard deviation of overall mean microleakage at adhesive interfaces at both the occlusal and gingival areas.

Table I: Mean and standard deviation of overall mean microleakage at adhesive interfaces at both the occlusal and gingival areas.

\begin{tabular}{|c|c|c|c|}
\hline Site & Study Groups & Mean & Std. Deviation \\
\hline \multirow{3}{*}{ Occlusal } & Group IA & 1.774 & 0.48927 \\
\cline { 2 - 4 } & Group IB & 1.1575 & 0.39193 \\
\cline { 2 - 4 } & Group IIA & 0.5365 & 0.56648 \\
\cline { 2 - 4 } & Group IIB & 0.4205 & 0.49129 \\
\hline \multirow{3}{*}{ Gingival } & Group IA & 2.3675 & 0.28707 \\
\cline { 2 - 4 } & Group IB & 1.5945 & 0.60162 \\
\cline { 2 - 4 } & Group IIA & 1.0445 & 0.62838 \\
\cline { 2 - 4 } & Group IIB & 0.776 & 0.51371 \\
\hline
\end{tabular}

Group IA: polycarbonate brackets bonded with light-cured resin modified glass ionomer.

Group IB: polycarbonate brackets bonded with light-cured composite resin.

Group IIA: metallic brackets bonded with light-cured resin modified glass ionomer.

Group IIB: metallic brackets bonded with light-cured composite resin. 
Table II showing the comparison of the mean microleakage values between the occlusal and gingival areas for adhesive interfaces. Statistical analysis was carried out using general linear model (GLM) test. The gingival areas of all groups exhibited higher microleakage values than the occlusal areas for adhesive interfaces (figures 2-5) and the differences were statistically significant $(\mathrm{P}<0.001)$. These results were represented graphically in figure using bar chart with error bars for 1.00.

Table II: Comparison of the mean microleakage values between the occlusal and gingival areas for adhesive interfaces.

\begin{tabular}{|l|c|c|c|c|c||}
\hline \multicolumn{1}{|c|}{ Source } & $\begin{array}{c}\text { Type III Sum of } \\
\text { Squares }\end{array}$ & df & Mean Square & F & P \\
\hline Site & 8.968 & 1 & 8.968 & 34.855 & $<0.001^{*}$ \\
\hline Group & 52.746 & 3 & 17.582 & 68.335 & $<0.001^{*}$ \\
\hline site * group & 0.308 & 3 & 0.103 & 0.400 & \\
\hline Error & 39.109 & 152 & 0.257 & & \\
\hline Corrected Total & 101.132 & 159 & & & \\
\hline R Squared = 0.613
\end{tabular}

$\mathrm{Df}=$ degree of freedom. $\quad \mathrm{F}=$ Annova. $\quad$ *Statistically significant at $(\mathrm{P}<0.001) .(\mathrm{N}=40)$

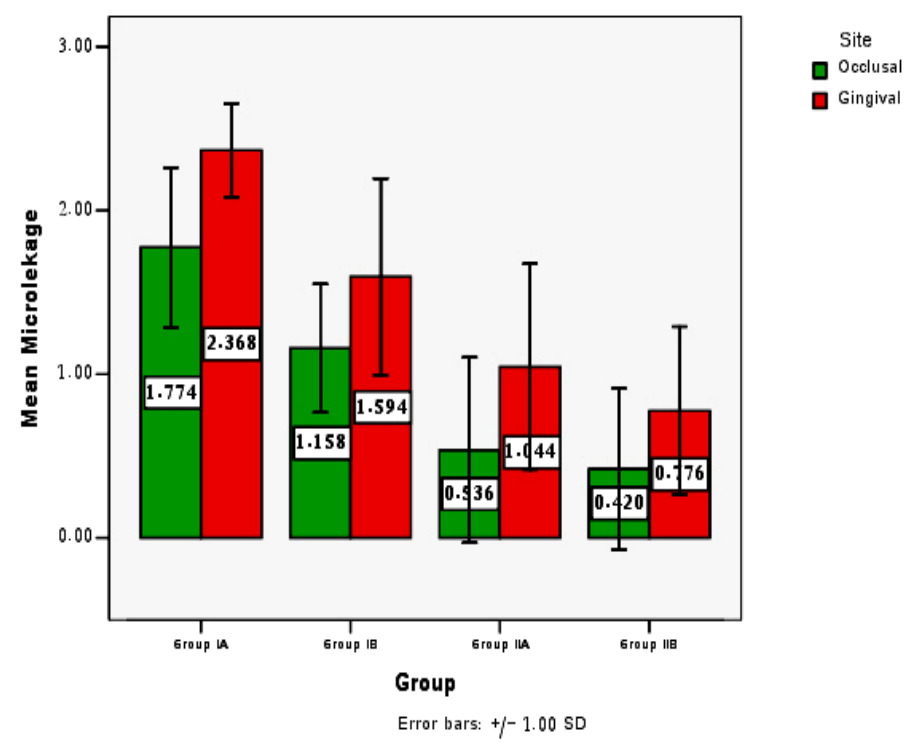

$$
\begin{aligned}
& \text { Site } \\
& \text { Occlusal } \\
& \text { Gingival }
\end{aligned}
$$

Fig. (1): Bar chart representing the meanmicroleakage values at the occlusal and gingival areas for adhesive interfaces. 


\section{Egyptian}

Orthodontic Journal

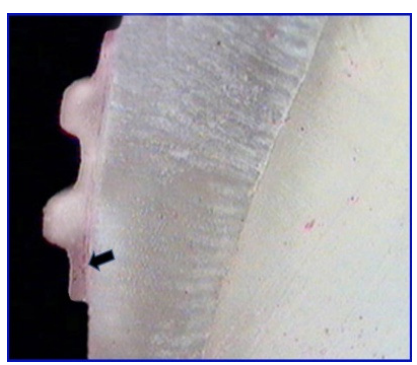

Fig. (2): Specimen from group IA showing gingival microleakage.

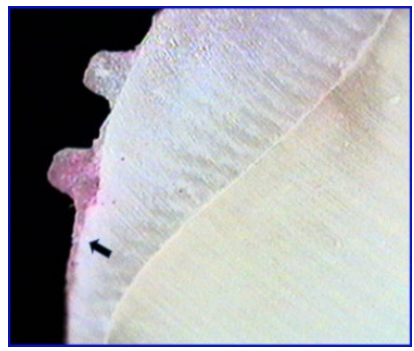

Fig. (3): Specimen from group IB showing gingival microleakage.

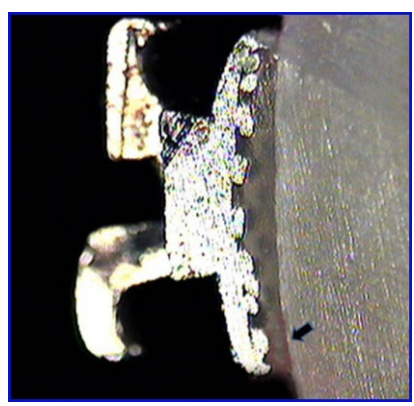

Fig. (4): Specimen from group IIA showing gingival microleakage.

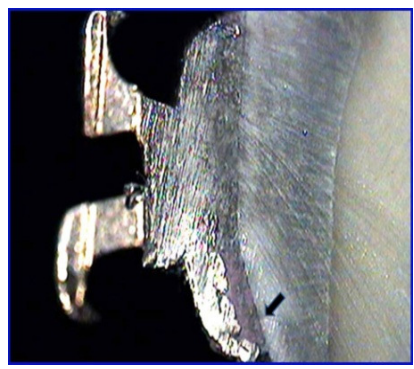

Fig. (5): Specimen from group IIB showing gingival microleakage. 
Table III shows the comparison among study groups as regards mean microleakage at adhesive interfaces. The difference in microleakage values between groups were statistically significant using Annova test with $(\mathrm{P}<0.001)$

Table III: Comparison among study groups as regards meanmicroleakage at adhesive interfaces.

\begin{tabular}{||l|c|c|c|c|c|}
\hline \multicolumn{1}{|c|}{ Groups } & (Group IA) & (Group IB) & (Group IIA) & (Group IIB) & Total \\
\hline Std. Deviation & 0.49708 & 0.54784 & 0.64411 & 0.52779 & 0.79753 \\
\hline Mean & 2.0708 & 1.376 & 0.7905 & 0.5983 & 1.2089 \\
\hline \multirow{2}{*}{ ANOVA test } & Sum of Squares & df & Mean Square & F & P \\
\cline { 2 - 7 } & 52.746 & 3 & 17.582 & 56.687 & $<0.001^{*}$ \\
\hline
\end{tabular}

*Statistically significant at at $(\mathrm{P}<0.001)$. ( $\mathrm{N}=40)$

Table IV and figure 6 show pairwise comparison between study groups as regards mean microleakage at adhesive interfaces. Utilizing Tukey HSD test showed that Group IA exhibited significant higher microleakage values than Group IB, Group IIA as well as Group IIB ( $\mathrm{P}<0.001)$. Group IB showed significant higher microleakage values than Group IIA, Group IB and Group IIB $(\mathrm{P}<0.001)$. While no Significant differences were observed between Group IIA and Group IIB (P=0.414). (Figs. 15, 16)

Table IV: Pairwise comparison between study groups as regards mean microleakage at adhesive interfaces.

\begin{tabular}{|c|c|c|c|c||}
\hline \multirow{2}{*}{ Groups } & Groups & Mean Difference (I-J) & Std. Error & P \\
\hline \multirow{3}{*}{ (Group IA) } & (Group IB) & 0.69475 & 0.12453 & $<0.001^{*}$ \\
\cline { 2 - 5 } & (Group IIA) & 1.28025 & 0.12453 & $<0.001^{*}$ \\
\cline { 2 - 5 } & (Group IIB) & 1.4725 & 0.12453 & $<0.001^{*}$ \\
\hline \multirow{2}{*}{ (Group IB) } & (Group IIA) & 0.5855 & 0.12453 & $<0.001^{*}$ \\
\cline { 2 - 5 } & (Group IIB) & 0.77775 & 0.12453 & $<0.001^{*}$ \\
\hline (Group IIA) & (Group IIB) & 0.19225 & 0.12453 & 0.414 \\
\hline
\end{tabular}

Tukey HSD test. $\quad *$ Statistically significant at at $(\mathrm{P}<0.001) .(\mathrm{N}=40)$ 


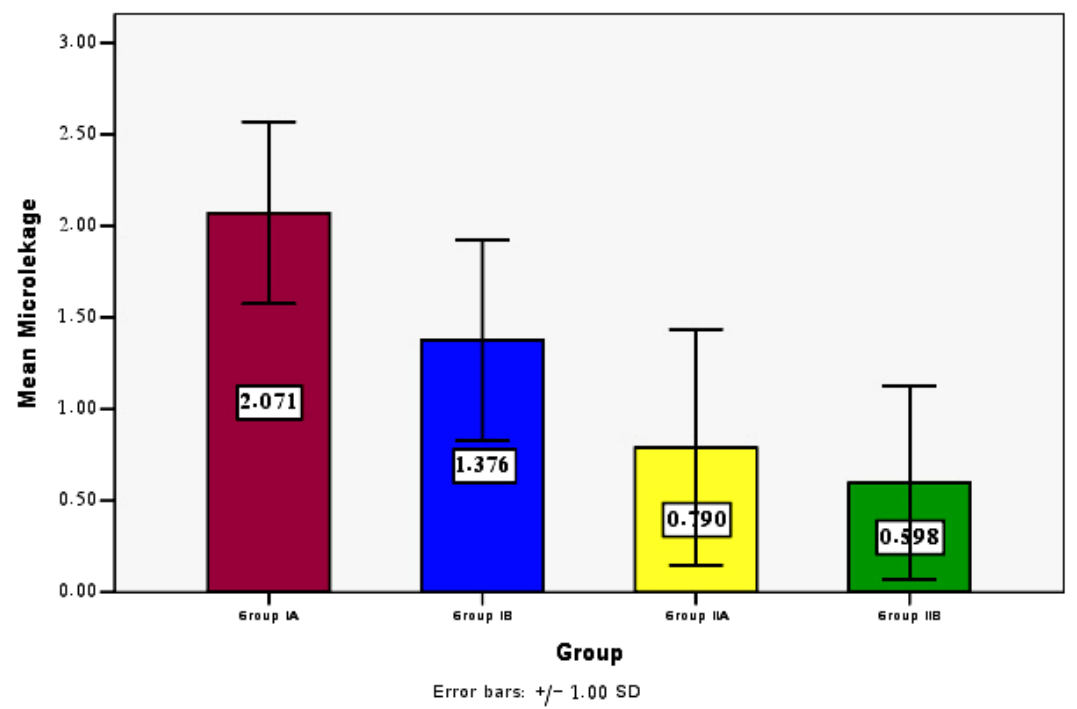

Fig. (6): Bar chart showing the mean microleakage in different study groups at the adhesive interfaces.

Table $\mathrm{V}$ shows the mean, standard deviationand comparison of the overall mean microleakage in specimens where RMGI and composite resin were used at adhesive-tooth interface regardless of the bracket type which displayed in Fig.15. The statistical analysis of data using $t$ test showed higher microleakage of RMGI specimens with $p<0.001$. (Figures. 7 - 9)

Table (V): Comparison of mean microleakage between adhesives.

\begin{tabular}{||c|c|c|c|c|c|}
\hline & Adhesive & Mean & Std. Deviation & t-value & P \\
\hline \multirow{2}{*}{ Microleakage } & RMGI & 1.4306 & 0.861 & \multirow{2}{*}{3.561} & $<0.001^{*}$ \\
\cline { 2 - 6 } & Composite & 0.9871 & 0.662 & & \\
\hline
\end{tabular}

$\mathrm{t}=$ student's $\mathrm{t}$ test.

* Statistically significant at at $(\mathrm{P}<0.001) .(\mathrm{N}=40)$.

Volume 42-December 2012 


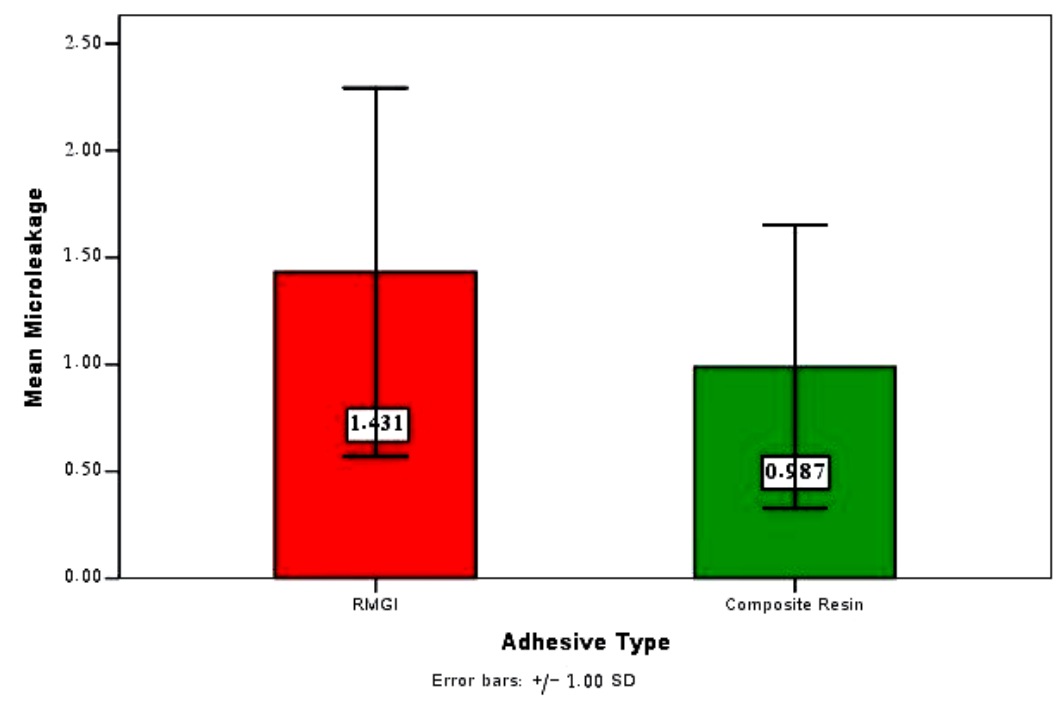

Fig. (7): Barchart showing meanmicroleakage between adhesives.

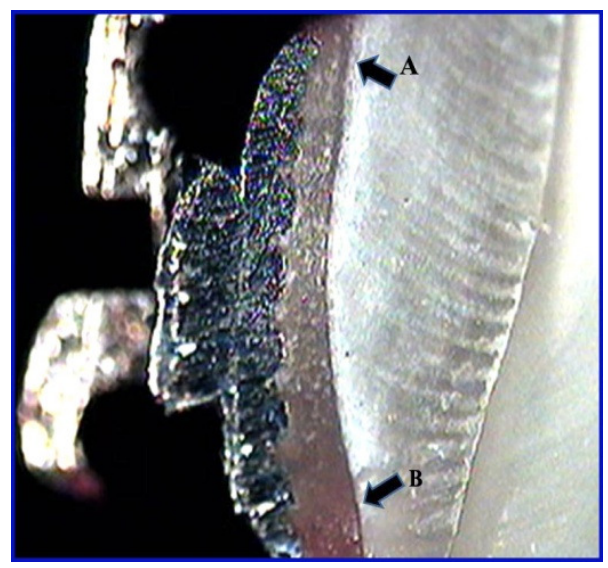

Fig. (8): Specimen from group IIB showing microleakage at gingival and occlusal areas.

A: Occlusal area, B: Gingival area. 
Egyptian

Orthodontic Journal

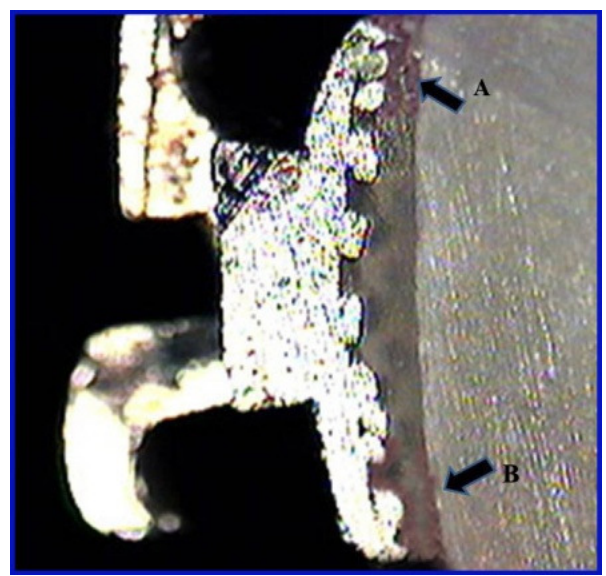

Fig. (9): Specimen from group IIA showing microleakage at gingival and occlusal areas.

A: Occlusal area, B: Gingival area.

\section{DISCUSSION}

Analysis of data regarding the overall mean microleakage value from both the tooth-adhesive interface and the bracket -adhesive interface revealed a significant higher microleakage values gingivally than occlusally in all groups, in accordance with many previous studies ${ }^{(17,18,19,20)}$ which observed that the differences between the gingival and the occlusal scores may be related to the surface curvature anatomy, which may result in relatively thicker adhesive at the gingival margin resulting in greater polymerization shrinkage and in turn increasing microleakage.

The mean microleakage values observed at the tooth-adhesive interface in all groups were similar to nearly all studies. ${ }^{(17,18,19,20,21,22)}$ This may be explained by the polymerization which starts initially at the adhesive material close to the light source, so it will harden in this region and move the free floating bracket closer to the tooth surface and the adhesive shrinkage far away from the light source will be changed so microleakage appear at the tooth-adhesive interface. ${ }^{(21,23)}$

When the overall microleakage values between RMGI and composite resin were compared at enamel-adhesive interface, we found 
that significant higher microleakage for Fuji Ortho LC than Transbond XT. That is related to the difference in the solubility of the adhesive material which plays an important role in microleakage, ${ }^{(24,25)}$ where the hydrophilic nature of RMGI cements showed higher dissolution and hydrolysis than composite. ${ }^{(26,27)}$ In concordance with Ramoglu et al (2007) ${ }^{(21)}$ who evaluated the microleakage under metallic and ceramic brackets bonded with RMGI and composite resin. They found that Transbond XT showed less microleakage than Fuji OrthoLC.

Comparing the mean microleakage values of reinforced polycarbonate brackets bonded with Fuji Ortho LC and Transbond XT with metallic brackets bonded with same adhesives revealed a significantly higher microleakage in reinforced polycarbonate brackets than the metallic brackets regardless of the adhesive type. This may be attributed to the weak bond strength of plastic bracket in comparison with conventional metallic one as reported in most studies. ${ }^{(28,29)}$ Moreover, this weak bond strength of the polycarbonate brackets were manifested in this study by the detachment of 2 brackets in the group bonded by RMGI and one bracket in the group bonded by composite resin following the thermocycling, while no detachment in the metallic bracket group was observed. The increased strength for metallic brackets may lead to the close adhesion of the bracket to the adhesive resulting in less microleakage.

Previous studies ${ }^{(17,30,31)}$ have shown the effects of microleakage on the durability of bonding, while in our study the microleakage may be the resultant and not the causative factor.

A similar concept was reported by Abdelnaby and Al wakeel $(2010)^{(30)}$ who found that significant negative correlation between bond strength and microleakage, thesis results disagreed with the results obtained by James et al (2003) ${ }^{(1)}$ who stated that no correlation was found between microleakage and bond strength. Also with a study held by Arhun et al (2006) $)^{(17)}$ who found that increased bond strength with ceramic brackets resulted in less microleakage compared with the weaker bond strength for metallic brackets and the resultant of more microleakage.

Significant higher microleakage values was recorded for ceramicreinforced polycarbonate brackets bonded with Fuji Ortho LC than those 
Egyptian

Orthodontic Journal

bonded with Transbond XT. This may be attributed to the bonding system used as most Bis-GMA adhesives provide enough bond strength for plastic brackets ${ }^{(28)}$ but the glass ionomer cement does not. ${ }^{(28)}$ The bond strength of plastic brackets differ from one type to another and this differences are due to different combination of bracket and adhesive ${ }^{(32)}$ In particular, the bond strength of Fuji Ortho LC was reported to have less strength than composite resin. ${ }^{(33,34,35,36,37)}$

Overall comparison of the bonding system used revealed that no combination was found to be superior in their microleakage inhibition property. Although the metallic brackets bonded with both the composite resin and resin-modified glass ionomer showed less microleakage than polycarbonate brackets. The polycarbonate brackets even by addition of ceramic fillers seemed that it was still inferior to the metallic brackets in this property.

\section{CONCLUSION}

1-The overall comparison of the bonding system used revealed that no combination was found to be superior in their microleakage inhibition property, although the metallic brackets bonded with both the composite resin and resin modified glass ionomer showed less microleakage than polycarbonate brackets. 2-The polycarbonate brackets even by addition of ceramic fillers seemed that it was still inferior to the metallic brackets in the microleakage inhibition property.

\section{REFERENCES}

1- James JW, Miller BH, English JD, Tadlock LP, Buschang PH. Effects of high-speed curing devices on shear bond strength and microleakage of orthodontic brackets. Am J Orthod Dentofacial Orthop. 2003; 123:555-61.

2- Bergenholtz G, Cox CF, Loesche WJ, Syed SA. Bacterial leakage around dental restorations: its effect on the dental pulp.J Oral Pathol.1982; 11:439-50.

3- Nunn JH, Ekanayake L, Rugg-Gunn AJ, Saparamadu KD. Assessment of enamel opacities in children in Sri Lanka and England using a photographic method. Community Dent Health. 1993; 10:175-88. 
4- Nunn JH, Rugg-Gunn AJ, Ekanayake L, Saparamadu KD. Prevalence of developmental defects of enamel in areas with differing water fluoride levels and socio-economic groups in Sri Lanka and England. Int Dent J. 1994; 44:165-73.

5- Gorelick L, Geiger AM, Gwinnett AJ. Incidence of white spot formation after bonding and banding. Am J Orthod. 1982; 81:93-8.

6- O'Reilly MM, Featherstone JD. Demineralization and remineralization around orthodontic appliances: an in vivo study. Am J Orthod Dentofacial Orthop. 1987; 92:33-40.

7- Newman GV. Adhesion and orthodontic plastic attachments. Am J Orthod. 1969; 56:573-88.

8- Garn NW. Direct bonding: a clinical study using an ultraviolet-sensitive adhesive system. Am J Orthod. 1976; 69:455-63.

9- Aird JC, Durning P. Fracture of polycarbonate edgewise brackets: a clinical and SEM study. Br J Orthod. 1987; 14:191-5.

10- Felder JC, Sarkar NK, Sheridan JJ, Lancaster DM. In vitro torque- deformation characteristics of orthodontic polycarbonate brackets. Am J OrthodDentofacialOrthop. 1994; 106:265-72.

11- Watt DC, Silikas N. In situ photo-polymerization and polymerization shrinkage phenomena. In: Eliades G, Watts DC, Eliades T. Dental Hard Tissues And Bonding Interfacial Phenomena And Related Properties. $5^{\text {th }}$ ed. Berlin: Springer, 2005. 123-54.

12- Costa Pfeifer CS, Braga RR, Cardoso PE. Influence of cavity dimensions, insertion technique and adhesive system on microleakage of class V restoration. J Am Dent Assoc. 2006; 137:197-202.

13- Bullard RH, Leinfelder KF, Russell CM. Effect of coefficient of thermal expansion on microleakage. J Am Dent Assoc. 1988; 116:871-4.

14- Arikan S, Arhun N, Arman A, Cehreli SB. Microleakage beneath ceramic and metal brackets photopolymerized with LED or conventional light curing units. Angle Orthod. 2006; 76:1035-40. 
15- Gale MS, Darvell BW. Thermal cycling procedures for laboratory testing of dental restorations. J Dent. 1999; 27: 89-99.

16- Marina FE, Bryant RW. Acid-etching of enamel cavity walls. Aust Dent J. 1984; 29:308-14.

17- Arhun N, Arman A, Çehreli SB, Arikan S, Karabulut E, Gulsahi K. Microleakage beneath ceramic and metal brackets bonded with a conventional and an antibacterial adhesive system. Angle Orthod. 2006; 76:1028-34.

18- Uysal T, Ramoglu SI, Ulker M, Ertas H. Effects of high intensity-curing lights on microleakage under orthodontic bands. Am J OrthodDentofacialOrthop.2010; 138:201-7.

19- Uysal T, Ulker M, Ramoglu SI, Ertas H. Microleakage under metallic and ceramic brackets bonded with orthodontic self-etching primer systems. Angle Orthod. 2008; 78:1089-94.

20- Ramoglu SI, Uysal T, Ustdal A, Ulker M. Evaluation of microleakage under precoated and uncoated brackets .J SU Dent.2010; 19:65-70.

21- Ramoglu SI, Uysal T, Ulker M, Ertas H. Microleakage under ceramic and metallic brackets bonded with resin-modified glass ionomer. Angle Orthod. 2007;79: 138-43.

22- Yagci A, Uysal T, Ulker M, Ramoglu SI. Microleakage under orthodontic brackets bonded with the custom base indirect bonding technique.Eur J Orthod. 2010; 32:259-63.

23- Yoon TH, Lee YK, Lim BS, Kim CW. Degree of polymerization of resin composites by different light sources. J Oral Rehabil. 2002; 29:1165-73.

24- Beriat NC, Nalbant D. Water Absorption and HEMA Release of Resin-Modified Glass-Ionomers.Eur J Dent. 2009; 3: 267-72.

25- Chandra S, Chandra S, Chandra G. Microleakage. Text Book of Operative Dentistry: with MCQs. New Delhi: Jaypee Brothers Medical Publishers, 2007. 206-11.

26- Meşe A, Burrow MF, Tyas MJ. Sorption and solubility of luting cements in different solutions. Dent Mater J. 2008; 27:702-9. 
Egyptian

Orthodontic Journal

27- Attin T, Buchalla W, Kielbassa AM, Helwiq E. Curing shrinkage and volumetric changes of resin- modified glass ionomer restorative materials. Dent Mater. 1995 ;11:359-62.

28- Blalock KA, Powers JM. Retention capacity of the bracket bases of new esthetic orthodontic brackets. Am J OrthodDentofacialOrthop. 1995; 107:596-603.

29- Harria AM, Joseph VP, Rossouw PE. Shear peel bond strengths of esthetic orthodontic brackets. Am J Orthod Dentofacial Orthop. $1992 ; 102: 215-9$.

30- Abdelnabya YL, Al-Wakeel EE. Influence of modifying the resin coat application protocol on bond strength and microleakage of metal orthodontic brackets. Angle Orthod. 2010; 80:378-84.

31- Kubo S, Yokota H, Sata Y, Hayashi Y. Microleakage of self-etching primers after thermal and flexural load cycling.Am J Dent. 2001; 14:163-9.

32- Liu JK, Chang LT, Chuang SF, Shieh DB.Shear bond strengths of plastic brackets with a mechanical base.Angle Orthod. 2002; 72:141-5.

33- Owens SE Jr, Miller BH. A comparison of shear bond strengths of three visible light-cured orthodontic adhesives. Angle Orthod. 2000; 70:352-6.

34- Coups-Smith KS, Rossouw PE, Titley KC. Glass ionomer cements as luting agents for orthodontic brackets. Angle Orthod. 2003; 73:436-44.

35- Kirovski I, Madzarova S. Tensile bond strength of a light cured glass-ionomer cement when used for bracket bonding under different conditions: an in vitro study. Eur J Orthod. 2000;22:719-23.

36- Shammaa I, Ngan P, Kim H, Kao E, Galdwin M, Gunel E, et al. Comparison of bracket debonding force between two conventional resin adhesives and resin-reinforced glass ionomer cement: an in vitro and in vivo study. Angle Orthod. 1999; 69:463-69.

37- Movahhed HZ, Ogaard B, Syverud M. An in vitro comparison of the shear bond strength of a resin-reinforced glass ionomer cement and a composite adhesive for bonding orthodontic brackets. Eur J Orthod. 2005; 27:477-83.

Volume 42 - December 2012 